\title{
«MANUEL REINA», TEXTO ESENCIAL DEL JOVEN RUBÉN DARÍO
}

\author{
Miguel Ángel Auladell PÉREZ \\ Universidad de Alicante
}

\section{Resumen}

Con el título de «Manuel Reina», el joven Rubén Darío escribe un poema que puede ser considerado como uno de los textos esenciales de la primera etapa de su trayectoria. Supone un homenaje y un reconocimiento al poeta cordobés, uno de los primeros modernistas españoles. El valor del poema, más que en su calidad compositiva, su intensidad lírica o su perfección estilística, reside en representar una prueba de la atención que el nicaragüense muestra por alguien al que toma como referente y siente como maestro y modelo, para llevar a cabo una revolución en la lírica, como la que emprendería tras algunos otros parecidos ejercicios dotadores de oficio. Asimismo, el poema «Manuel Reina» acumula el carácter de texto con valor histórico-literario, propio de la que sería una de las facetas más cultivadas por Darío, no solo en su producción periodística y como crítico, sino también en sus versos.

Palabras clave: Rubén Darío. Manuel Reina. Origen del Modernismo. Poesía lírica.

\begin{abstract}
With the title «Manuel Reina», young Rubén Darío writes a poem that can be considered as one of the essential texts of the first part of his career. It is written to pay homage to Manuel Reina and in recognition of the poet from Córdoba, one of the first Spanish modernistas. The poem is not only valuable for its composing quality, its lyric intensity or its stylistic perfection, but for showing the attention of the poet from Nicaragua to someone who is a referent for him, and a master and a model, in order to perform a lyric revolution, similar to his revolution in the same kind of exercises which provide him with experience. Moreover, the poem «Manuel Reina» is a type of text with historic and literary value, which is characteristic of one of Dario's most cultivated facets, not only in his journalistic production and as a critic, but also in his lines.
\end{abstract}

Keywords: Rubén Darío. Manuel Reina. Origin of Modernismo. Lyric poetry. 
«Manuel Reina» es el título de un poema de juventud de Rubén Darío (18671916) y puede ser considerado un texto esencial de dicha etapa de su producción literaria. Alfonso Méndez Plancarte lo incluye en su edición de las Poesías completas (1961, p. 203) con indicación de la fecha de composición en octubre de 1884'; el autor, por tanto, contaría con diecisiete años al escribirlo. El poema suele quedar incluido en la sección «Homenajes y estelas» del conjunto poético titulado «La iniciación melódica», perteneciente a las rotuladas por el filólogo mexicano como Poesías dispersas hasta el Viaje a Chile, 1880-1886. En gran medida, se trata de un ejercicio del joven poeta en el que reconoce un magisterio proveniente de la Península Ibérica y anuncia una esperanza. Desea vehementemente que Manuel Reina (1856-1905), poeta cordobés de Puente Genil, llegue a configurar un poema excelso, sublime, contenedor de todos los ricos filones apuntados a lo largo del texto: «...Si él quisiera / escribir un poema, nos haría / a los amantes de lo bueno y bello / un gran servicio» (vv. 129-132). Nos inclinamos, pues, a hablar de poema esencial del joven Darío en el sentido en el que, generalmente, podemos atribuir al término esencial su más pleno significado. No obstante, adelantamos desde el principio que contamos con la particularidad de que el poema en cuestión no es precisamente un gran poema; no lo es técnica ni estéticamente. Otro cantar podemos escuchar si apreciamos su valor histórico-literario en relación con, al menos, dos fuentes de interés: una, la temprana construcción de Rubén Darío como poeta transatlántico ${ }^{2}$ y otra, el controvertido papel desempeñado por el poeta en la génesis del Modernismo. Por lo tanto, lo que trataremos de explicar es por qué adquiere relevancia la atención a este poema del joven nicaragüense en un contexto como el actual en el que intentamos recuperar el acercamiento a los textos y la reivindicación de los mismos.

Comenzamos citando, ya que conmemoramos año cervantino, unos versos del escritor alcalaíno:

Dijo Mercurio: «Quiero que me nombres

desta turba gentil, pues tú lo sabes,

la alteza de su ingenio, con los nombres».

Yo respondí: «De los que son más graves

diré lo que supiere, por moverte

a que ante Apolo su valor alabes».

Él escuchó. Yo dije desta suerte.

1. El año 1884 fue el de la publicación de Los poetas malditos ( $2^{\mathrm{a}}$ versión aumentada y definitiva en 1888), de Paul Verlaine. «Pauvre Lelian» se ocupaba de su propia obra y de la de otros cinco poetas franceses incomprendidos.

2. Así lo denominaba el venezolano Rufino Blanco Fombona en el poema que dedicó al autor tras su muerte: «el divino poeta transatlántico» (J. Delgado, 1967, pp. 289-290). 
Unos versos extraídos del Viaje del Parnaso, que nos recuerdan nuestra rica tradición de poetas que escriben sobre la poesía y los poetas. Lo que trato es de que, a través de este poema titulado «Manuel Reina», a través de ese nombre, podamos acercarnos a lo que es una recurrencia en Darío, una recurrencia que es parte de nuestra historia literaria. La costumbre está en el Viaje del Parnaso (1614) de Cervantes, está en el Laurel de Apolo (1630) de Lope de Vega y está en tantas y tantas otras obras en las que uno de nuestros escritores, uno de nuestros creadores del idioma hace crítica literaria, repasa sus lecturas, apunta unas posibilidades de canon literario y, en definitiva, selecciona unos textos esenciales para él, teniendo en cuenta su mayor o menor atractivo, para criticarlos desde un punto de vista positivo o, incluso, para arremeter fuertemente contra ellos. A la altura del tiempo de Manuel Reina y de Rubén Darío, esa práctica alcanza unos niveles de gran rendimiento artístico. Los parnasianos habían hecho acto de presencia en la escena y habían hecho evolucionar dicha práctica a través del correlato objetivo. A partir de ahí, el camino hacia la poesía culturalista estaba proyectado, casi delineado. En España, uno de los primeros que lo va a transitar va a ser nuestro cordobés (G. Díaz-Plaja, 1967, pp. 42-53). En América, Rubén Darío logrará hallazgos verdaderamente sobresalientes en dicha práctica.

Como decíamos más arriba, el poema «Manuel Reina» se ha editado dentro del conjunto poemático escrito en tierra de Rubén y en otros países centroamericanos. Se trata de un conjunto de poesías dispersas que van desde los primeros pinitos realizados hasta las piezas que ya va a escribir a partir de su viaje a Chile y de su estancia posterior en diversas capitales del continente. En concreto, por tanto, un corpus textual que vendría a estar fechado entre 1880 y 1886 , es decir, el compuesto durante la primera juventud del poeta, bastante tiempo antes de la publicación en Valparaíso (Chile), en 1888, de su libro Azul... y, por tanto, durante unos años que, si son algo, son, desde luego, un período de formación. Este extremo quiero subrayarlo. Esos años son los de la construcción de un poeta que, como es bien sabido, desde bien pequeño -se le llamó desde muy temprano el «poeta niño»-, desde muy corta edad rimó, versificó y se acostumbró prácticamente a que todas sus emociones habían de transmitirse a través de esa escritura que, fundamental y retóricamente tenía que ver con la métrica, con el ritmo, con el estrofismo y con todo lo que representa la versificación del lenguaje poético. Siempre ha sorprendido la precocidad del nicaragüense de Metapa para la versificación. Él mismo reparó en ello al escribir en su Autobiografía: «Yo nunca aprendía a hacer versos. Ello fue en mí orgánico, natural, nacido». Teodosio Fernández (1987, p. 10) subraya muy a propósito las palabras de Edelberto Torres, uno de los mejores 
biógrafos de Rubén, cuando llega a comentar cómo en la ciudad donde se crio el poeta, todo se veía salpicado de versos:

En León se versifica por cualquier menudo acontecimiento social: epitalamios para una boda, elegías por un deceso, epigramas por un cumpleaños, epinicios por una victoria política o militar, silvas laudatorias por la consagración de un obispo y hasta por la toma de posesión de un empleo. Ni para qué decir que la más constante fuente de rimas es el amor a las Fléridas, Doroteas y Filis locales.

Si nos fijamos en el texto que titula el joven Rubén con el nombre de «Manuel Reina» y lo ponemos en relación con otros poemas escritos en esos mismos años, nos apercibimos de estar ante la exposición de una especie de álbumes. Tenemos un álbum en el que vemos diversas imágenes del poeta cordobés de Puente Genil, un poeta que, a la sazón, contaba con un creciente prestigio literario en la Península, que se dejaba traslucir en una importante presencia pública, prácticamente en todas las cabeceras de la prensa periódica más destacada. Asimismo, había realizado dos poemarios, que había dado a luz: Andantes y alegros [sic] (1877) y Cromos y acuarelas (1878). Era un ser exquisito, era una persona coleccionista de ediciones primorosas, de pintura, de todo tipo de objetos, de antigüedades. Por tanto, muchos de los jóvenes de este lado del océano y también del otro, admiraban esa posición que despuntaba entre los poetas de su generación y, pese a tener tan grandes huellas de la poesía civil, esa reiteradamente aludida conexión con un poeta tan relevante de ese tipo de género poético como era don Gaspar Núñez de Arce, representaba una manera muy distinta de mostrar la figura del poeta en la sociedad y ofrecía, además de elementos de raigambre romántica como vate (vates, vatis: profeta, adivino), un nuevo camino, una nueva posibilidad de acercamiento. Es siempre iluminador el magisterio de uno de los mayores comentaristas de los textos darianos, el argentino Antonio Marasso (1934, p. XVI). Unas palabras suyas pueden servirnos de guía para dilucidar el valor que para el joven Rubén tuvo la asimilación de una obra poética como la de Manuel Reina:

Este Darío de retortas y crisoles, fue el Darío innovador y, al mismo tiempo, escritor sincero y personal, porque las adquisiciones incesantes se transforman en cosa propia, en un idioma en el cual expresaba su original manera de ver, de sentir, con el ritmo de una armonía extraña; son «los elementos, como él dice, que constituirían después un medio de manifestación individual».

Si nos centramos en el propio texto de Darío, titulado «Manuel Reina», vemos, como decía al principio, el poema de un joven, un joven que aún no ha logrado un estilo acendrado, que es bastante vacilante en cuanto a qué formas escoger para ir presentando a este peninsular, a este cordobés, al que 
él, seguramente, admira, pero al que también se acerca por algún tipo de recomendación que le sugiere escribir unos versos encomiásticos. En todo caso, querámoslo o no, dedica casi doscientos versos al personaje y, por tanto, no estamos ante un ejercicio trivial, sino ante algo marcador, algo con valor de manifiesto, al menos en ese período inicial de escritura poética antes de marchar para Chile.

Destaco del poema la primera alusión a otros grandes nombres del Olimpo español de entonces. Curiosamente, cuando empieza, cita enseguida a ese poeta que he nombrado líneas atrás, Gaspar Núñez de Arce. También cita a José Zorrilla, que, por cierto, había tenido una presencia americana notable, en México. Se recrea en cubrir todo el verso 15 con el inmenso patronímico de Ramón de Campoamor y Campo Osorio, aprovechando esa extensión-duración con finalidad retórica, al recordar el gigante que era literaria y físicamente don Ramón de Campoamor. Hace esos juegos simbólicos, comparando el referente con la manera de conformar el verso y luego ese Manolo del Palacio, no Manuel, para ajustar el metro endecasílabo y propiciar el acercamiento al que es precisamente el escritor más festivo, satírico, presente en la prensa jocosa, burlesca y que tanta fama tuvo al otro lado del Atlántico. Entre medias queda Echegaray, calificado como «emperador del teatro», personalidad con ascendiente sobre muchos de los jóvenes del momento, incluido el propio Manuel Reina, que le encargaría artículos en su revista La Diana ${ }^{3}$, para, entre otras cosas, divulgar los adelantos científicos relacionados con la electricidad. Es conocida, por otro lado, cómo cambió la perspectiva hacia nuestro primer Premio Nobel de Literatura cuando, algunos años más tarde, se produjo la contestación que desató una dura campaña para oponerse a que le concediera su galardón la academia sueca. Todo ese huracán de desprestigio ha oscurecido su figura, aunque también fue reivindicada por Azorín en el primer artículo de los cuatro que con el título de «La generación de 1898», publicó en febrero de 1913, en el diario $A B C$. José Echegaray fue uno de los intelectuales del momento más atento a las evoluciones literarias que se estaban llevando a cabo en el ámbito americano. De hecho, mantuvo una gran relación intelectual con Martí cuando estuvo en la Península (Esteban-P. Del CAmPo, p. 145). Incido en ello, porque hoy en día la imagen de Echegaray es la de un escritor muy fosilizado y convendría repasar lo que significa ese Echegaray

3. La revista La Diana, dirigida por Manuel Reina, tuvo enorme ambición y gozó de la colaboración de algunos de los escritores más representativos de su tiempo. En ella, Clarín publicó sus artículos sobre el Naturalismo. El subtítulo, Revista quincenal de Política, Literatura, Ciencias y Artes, apuntaba el carácter misceláneo y abierto de la publicación. 
atento a la novedad, como simple lector, como personaje que disfruta de la literatura. ¿Habría alguna duda respecto a lo que representaron los cuatro primeros nombres señalados aquí? Al añadir el de José de Echegaray, asistimos una vez más, a cómo Rubén Darío nos pone sobre la pista.

Va enumerando a continuación una serie de rasgos que podríamos denominar característicos de Manuel Reina. Habla de su estilo como «un estilo sui géneris / difícil de imitar». Voy desgranando algunos de los elementos que pueden destacarse a partir del propio texto. Insisto en que no me detengo en celebrar las calidades del poema del joven Darío, que las tiene sin duda. Me interesa, sobremanera, fijarme en el amplio abanico de "epítetos épicos" con los que ofrece una imagen de Manuel Reina como poeta-artista, como referente para un joven como él; y todo ello porque puede servir para explicarnos mejor lo que quiero defender aquí. Cuando entra en liza la alusión directa a Manuel Reina (v. 22), el autor del poema anota que "Entre ellos tiene alto puesto». El primer halago consiste en considerar al joven poeta español a la altura de los consagrados escritores mencionados. En el mismo verso utiliza el término «vate» $y$, seguidamente, añade:

Muestra Reina un estilo sui géneris

difícil de imitar; esto en la forma, que lo que es en la idea, es un poeta del siglo diecinueve a todas luces.

El jovencito que escribe en tierras lejanas a la Península, no engaña a nadie. Percibe muy bien y se da cuenta muy bien de qué tipo de poeta es Manuel Reina. Lo que sucede es que, si le dedica un poema tan extenso, cercano a los doscientos versos, y seguro de tono encomiástico en su mayor parte y, en gran medida un verdadero panegírico, es también porque intenta aprovechar determinadas cualidades de su innovación formal y de su tarea como poeta y como promotor literario. Trataremos de verlo a lo largo de estas líneas.

Rubén Darío se muestra preocupado por cuestiones que debe ir despejando para pulir con oficio el diamante que guarda en su interior. Alude en el poema a rasgos característicos de una línea de práctica poética que bebe en la estética romántica, pero, al mismo tiempo, repara en ese gusto por el decadentismo y por el parnasianismo -en el que, desde luego, militó el primer Manuel Reina-, que se manifiestan en versos como el que afirma que:

...Reina os contará cosas distintas (v. 35).

$\mathrm{O}$ aquellos en que haciendo uso de la amplificatio, detalla los itinerarios poéticos y las preocupaciones turbadoras del poeta cordobés: 
Él os dará la mano, y poco a poco

os llevará al bullicio de las cortes; os mostrará los rostros descompuestos en medio de la orgía, en las ciudades, y copas de champaña a vuestros labios acercará; y al son de las alegres carcajadas y ruidos bulliciosos, entonará sus cánticos extraños (vv. 36-43)

El componente musical aflora en los versos antedichos y cobra protagonismo en los que siguen. El joven Darío concibe la poesía como arte musical. El ritmo y la melodía son consustanciales al lenguaje poético. Esa certeza le hace valorar los efectismos sonoros que atesora la versificación de Manuel Reina. Esos «cánticos extraños» se van sucediendo, se entonan con elegancia y brío lírico. Se sabe que Reina admiró profundamente la poesía alemana y se mostró muy influido por la obra de Heine. Rubén nos lo expresa así, dando muestras del conocimiento que posee de la obra del cordobés:

$[\ldots]$ ya resuena
su nota vibradora y dulce siempre.

Son sus versos raudal de melodías

derramadas, $[\ldots]$

[...], ofrece

notas, suspiros, ecos, ritmos, sones,

deleitosos a veces, siempre gratos

y llevando un torrente de armonías.

Si alemán fuera el bardo, iqué baladas

no saldrían de su estro! [...] (vv. 49-52 y 64-68).

Como había ocurrido con el mismo Bécquer, Manuel Reina se había inclinado por determinados poetas románticos alemanes. Poetas que habían llevado a cabo en su idioma una nueva manera de composición poética. En un principio, para el joven Rubén era tremendamente estimulante el hecho de que Manuel Reina fuera un admirador de Heine y así lo valora:

[...] Mas prefiero que cante en español esas estrofas (vv. 68-69).

Uno de los motivos por los que me interesa destacar el valor de este poema es porque a través del mismo vemos cómo Rubén Darío se empieza a convertir en el poeta de dos mundos. Pedro Salinas, que se refirió a esta etapa productiva de Darío como la prehistoria de su trayectoria, afirmaba que llegó a transfigurarse en el gran alambicador, el gran sintetizador, el que en su escritura había hecho una labor sincrética de la «España heredada» y la «España ganada». "Mas prefiero / que cante en español" es todo un alegato. Rubén va 
a configurar una nueva voz de nuestro idioma. Borges habló de cómo su obra capital consistió en afinar su música. Antonio Colinas se ha referido a «la estirpe netamente órfica de su canto» ${ }^{4}$. Logrará el empeño componiendo una sugestiva música transportadora al espacio del azul... El joven poeta ve en Manuel Reina un peregrino de ese camino y resalta:

[...] Esas estrofas

que son bellos, preciosos ramilletes

de flores de pulida filigrana.

A las veces, se torna rudo y grave,

y entonces pulsa el arpa resonante

[...] los espíritus

que vuelan agitando las tormentas

en el azul, se acercan, le rodean; (vv. 69-73 y 76-78).

Más adelante, reitera dicha vertiente musical del autor de Andantes y alegros que nos deleita :

...produciendo raras sinfonías

en loca exaltación (vv. 84-85).

El verso inicial del poema dice: «Tiene España poetas inspirados». Al llegar el verso 86, se atreve también, por fin, a llamar «poeta inspirado» a Manuel Reina. Parece que ha querido preparar al lector o al oyente. Pero, asimismo, el tramo recorrido aleja a Reina del lado de los próceres reconocidos y le instala en una atalaya que adquiere autonomía e independencia y le consagra como un modelo o, al menos, un referente más cercano a las inquietudes del joven nicaragüense.

Nos repasa cuáles son sus exotismos, cuáles son sus temas, sus intereses. Comienza de una manera vehemente viendo cómo Reina se detiene en lo medieval. Recuérdense elementos, no sólo del decadentismo o del parnasianismo, sino también del componente prerrafaelita, en ese viaje a la Edad Media, que es un viaje superador de ese materialismo atroz a donde ha llevado la vulgaridad de la clase burguesa y, entonces, ese joven Rubén se ve llamado, como Manuel Reina, a irse hacia esos mundos medievales:

$$
\begin{aligned}
& \qquad \text { La Edad Media } \\
& \text { tiene para él encantos y atractivos } \\
& \text { que sabe aprovechar en sus canciones; (vv. 86-88) }
\end{aligned}
$$

Repara más tarde en lo que son sus técnicas más recurrentes; sobre todo, en el caso de Manuel Reina, curiosamente -como luego se dirá tantas veces del

4. El Cultural, 24/01/08, p. 21. 
propio Rubén Darío- lo más destacado desde el punto de vista de la forma, del estilo, de la expresividad, es esa calidad musical y ese aprecio por el cromatismo, incluso por el simbolismo cromático: "¡Y esto, con qué colores!" -dice en el verso 93.

Vuelve otra vez a dejar claro qué tipo de poeta es:

[...] Reina es un poeta

del siglo diecinueve, neto y llano (vv. 95-96).

Desde nuestra perspectiva, ese tipo de calificación parece limitadora para la consideración de Manuel Reina como poeta del momento. No obstante, puede entenderse al revés. Al reafirmar a Reina como «poeta del siglo diecinueve», Rubén lo instala en su tiempo, en la actualidad, en la modernidad. Antonio Gallego Morell subrayó este extremo y lo documentó al fijarse en el subtítulo del segundo libro del cordobés que, de manera sutil, nos apunta hacia esta interpretación: Cromos y acuarelas (Cantos de nuestra época). Si había alguna duda, esta queda despejada al emprender el más obsequioso de los pasajes del poema respecto a la calidad lírica de Manuel Reina:

No es un cantor vulgar.

[...] es el género de Reina

original de suyo. Es lindo y raro

ese arrebatador procedimiento.

Finura y elegancia son sus bases,

pulcritud y entusiasmo sus adornos.

[...] Ofrece himnos ardientes

que exaltan el patriótico entusiasmo (vv. 99-104 y 106-107).

Este último enunciado acerca de los «himnos ardientes» y el "patriótico entusiasmo» atrae al que iba a componer al poco tiempo su Canto a las glorias de Chile. Es otro mérito añadido el hecho de disponer del cantor épico, de apreciar esa condición. A continuación, Rubén nos lleva a otro escenario en el que el poeta Reina:

Penetra en la arboleda, (v. 108)

La selva sagrada, lo edénico, lo paradisíaco, el terreno del misterio, la posibilidad de salvación constituyen toda una iconografía y una tematología propias de la época y anunciadoras de las corrientes estéticas finiseculares. Todo ello transido del potente empuje impulsado por la pasión. Manuel Reina visitará en otras obras posteriores territorios que alcanzan hasta la pasión mística, expresión muy empleada en la época y que sirvió a Baroja hasta para un subtítulo, el de su novela Camino de perfección (1902). 
Más adelante, contamos con un momento de clímax en el poema. El deudor parece que se torna en acreedor:

Éste es el gran poeta. Si él quisiera

escribir un poema, nos haría

a los amantes de lo bueno y bello

un gran servicio. Pulse, pues, la lira,

y resuenen sus cánticos soberbios

en una obra inmortal de gran aliento (vv. 129-134).

Claro, la cuestión es, si llegados a este punto, cabe preguntarse: ¿Asistimos a una reconvención dirigida a Manuel Reina, por parte del joven Rubén Darío? Debe observarse que, después de hacer todo este relato encomiástico del cordobés, le inquiere para que se centre y que, por fin, nos dé un gran poema:

¡Sí; que escriba un poema revestido

con esas joyas que sólo él fabrica

y con esas ideas altas, sumas,

que hay entre la cabeza de los seres

favorecidos por la augusta y santa

disposición del Cielo! [...] (vv. 135-140)

Y al final de la sección estrófica confía en que supere el apartamiento y se nutra de lo mundanal para cobrar fortaleza:

¡Dé vida al ideal, fuerza al espíritu,

y salga ufano recorriendo el mundo [...] (vv. 148-149).

Rubén habla en el verso 154 de su «alta inspiración», en los versos 167-169 le define como «poeta / que mil veces altísimas regiones / ha recorrido». Y termina el poema con versos que consagran la figura de Manuel Reina: «Ya conoce el Pindo / y ha libado en la copa de los dioses / el celeste licor» (vv. 169-171). Ha subido al sagrado monte. Sabe «sonar la dulce cítara armoniosa» (v. 173). La estrofa final es apoteósica:

Reina es poeta

que mil veces altísimas regiones

ha recorrido, ufano caballero en el Pegaso. Ya conoce el Pindo

y ha libado en la copa de los dioses

el celeste licor. Reina se sube cuanto ha deseado al sacro Olimpo; y sabe sonar la dulce cítara armoniosa, ora apacible como el son del aire entre la umbría retirada, y ora conmovedor y rudo como el trueno que ronco en el abismo se dilata. 
Este despliegue está realizado en una de las formas más habituales escogidas por el joven Rubén para componer las piezas de tipo encomiástico que acomete en esa etapa. Pero consideramos que puede repararse en otro extremo interesante. La forma elegida para su loa a Manuel Reina emplea la versificación emulando a la del propio poeta de Puente Genil. El grueso de la que podríamos calificar de silva está compuesto por diez secciones estróficas que imprimen una perspectiva temática, estructural y rítmica a la tirada de un total de 177 versos, endecasílabos en su mayoría: $1^{a}$ (vv. 1-23); $2^{a}$ (vv. 24$35) ; 3^{a}$ (vv.36-50); $4^{a}$ (vv. 51-71); $5^{a}$ (vv. 72-86), el último es heptasílabo; $6^{a}$ (vv. 87-94), el primero es pentasílabo; $7^{a}$ (vv. 95-128); 8 (vv. 129-151); $9^{a}$ (vv. 152-166), el último es heptasílabo; y $10^{a}$ (vv. 167-177), el primero es pentasílabo. Como podemos apreciar, el juego polimétrico es poco generoso, pero funcional. La rima no se cumple de manera estricta, pero predomina la asonante. En general, contamos con versos endecasílabos combinados en momentos puntuales con pentasílabos y heptasílabos.

Si he hecho este detenido repaso, es porque quería destacar no tanto la calidad a que nos tiene acostumbrados Rubén Darío, sino el coraje con el que construye un poema encomiástico y, a la vez, afectivo. Subrayo el hecho de que cuando compone el poema, tiene diecisiete años; es un joven que hace continuamente ejercicios de escritura y ha realizado toda esta composición de halago a ese poeta español al que él profesa admiración. Lo que he intentado es recalar en los aspectos a los que me refería en un principio. El hecho de ver a un Rubén que es capaz de efectuar un ejercicio de crítica literaria, al mismo tiempo que hace ese poema encomiástico. Además, este texto y algunos otros propician una posibilidad de conexión con la antigua metrópoli; en aquella fecha, aún metrópoli para algunos, como por ejemplo para los cubanos. El joven poeta centroamericano lo tendrá más fácil en los círculos literarios españoles cuando acuda a los mismos durante su primer viaje a Europa, el primer viaje a la Península, que, como es sabido, se producirá en 1892.

Rubén Darío volverá años más tarde a ocuparse de Manuel Reina. Es otro Rubén Darío, es ese Rubén Darío que ha evolucionado desde «el que fue» -como dice José Carlos Rovira, en su edición de la Obra poética (2011, p. XXVIII) ${ }^{5}$-, ese Rubén Darío que está trabajando como corresponsal para La Nación de Buenos Aires. Hace poco que se ha producido la derrota de España ante los Estados Unidos de Norteamérica y el autor nicaragüense va remitiendo crónicas -escritas desde el 3 de diciembre de 1898 al 7 de abril de 1900- y,

5. Rovira escribe: «Creo por tanto que el primer Darío es el que fue, el que escribe aquellos poemas iniciales que anuncian el aliento creativo posterior».

Anales, 28 (2016), pp. 15-38 
con el tiempo, esas crónicas, que parece solicitó realizar voluntariamente, darán lugar a ese libro imprescindible que es España contemporánea ${ }^{6}$ (1901). Antonio Vilanova lo califica de «vasto retablo histórico y sociológico de la España finisecular, en los días inmediatamente posteriores al desastre colonial del 98» (Darío, 1987, p. 9). En una de las crónicas que envía a la capital argentina, titulada "Los poetas" (24.08.1899), sorprendentemente o no tanto, nos habla otra vez de esos personajes que sirvieron al jovencito Rubén para empezar aquel poema de 1884, es decir, Campoamor, Núñez de Arce, Manuel del Palacio, José Echegaray y, claro está, el mismo Manuel Reina. El cordobés de Puente Genil acababa de publicar uno de sus libros más valorados por la crítica, El jardín de los poetas (1899). El poemario culturalista de Reina hace decir lo siguiente a Darío:

Manuel Reina ha logrado recientemente un triunfo con su Jardín de los poetas. Lírico de penacho, en color un Fortuny. Ha llamado la atención desde ha largo tiempo, por su apartamiento del universal encasillado académico hasta hace poco reinante en estas regiones. Su adjetivación variada, su bizarría de rimador, su imaginativa de hábiles decoraciones, su pompa extraña entre los uniformes tradicionales, le dieron un puesto aparte, alto puesto merecido. Le llaman discípulo e imitador del señor Núñez de Arce. No veo la filiación, como no sea en la manera de blandir el verso. Núñez de Arce es más severo, lleva armadura. Reina va de jubón y gorguera de encajes, lleno de su bien amada pedrería. No hay versos suyos sin su inevitable gema. En el Jardín de los poetas se ven sus preferencias mentales, un tanto en choque, por la variedad de las figuras. Su jardín es trabajo de virtuoso. Cada poeta le da su reflejo, y él aprovecha la sugestión felizmente.

La verdad es que después de leer estas palabras de Darío en el texto que más tarde recogería en España contemporánea, tenemos una posibilidad de ampliación de lo que era ese poema del joven Rubén en 1884, pero una ampliación en la que sigue presente una serie de constantes y que, claro está, viene a propósito de lo que es el aprovechar la publicación del libro más culturalista de Manuel Reina, El Jardín de los poetas ${ }^{7}$, en donde el propio cordobés también establece su gusto literario, su gusto poético, exalta una serie de nombres, da un repaso crítico-literario por ellos y crea una especie de canon de lecturas

6. La primera edición de la recopilación de artículos apareció en la capital francesa: España contemporánea. Crónicas y retratos literarios, París, Garnier, 1901.

7. José Luis García Martín (1986, p. 207) ha recuperado el nombre del poeta cordobés al estudiar la poesía culturalista de la posguerra española: «El olvidado Manuel Reina resulta un claro precursor de Rubén Darío en lo que a la utilización de elementos culturalistas se refiere. En 1899 dedica un libro íntegro, titulado El jardin de los poetas, a las evocaciones literarias. Las más diversas literaturas se encuentran representadas en esas páginas $[\ldots] »$. 
para la generación poética del momento. Rafael Alarcón Sierra (2002, p. 85) ha señalado cómo Manuel Reina dedicó un poema a «Góngora» en El jardín de los poetas (1899), y en el mismo año Rubén Darío hacía protagonista a este, junto a Velázquez, de su «Trébol» de sonetos.

Fijémonos ahora en cuál ha sido la transmisión del poema «Manuel Reina». En principio, esta puede ser calificada de azarosa. Habitualmente, se ha prescindido de nuestro poema a la hora de editar a Rubén Darío. No es, en efecto, el poema más querido por los antólogos, aunque en las últimas décadas sí que ha sido algo más recogido. La reivindicación de su valor marcador en la etapa de juventud de la trayectoria de su autor puede contribuir a que su presencia aumente cuando se reedite la poesía de Rubén. Creo que la inclusión del poema en la Antología de poesía y prosa que publiqué en la editorial Aguaclara era la primera que se realizaba (M. Á. Auladell, 1990, pp. 24-29), tras la presencia del texto en la edición conmemorativa del cincuentenario, la preparada por Alfonso Méndez Plancarte y Antonio Oliver Belmás (Darío, 1968). Recientemente, se ha incluido en la edición de la obra poética, preparada por Julio Ortega y publicada por Galaxia Gutenberg/Círculo de Lectores (Darío, 2007, pp. 867-872).

El poema «Manuel Reina» es un texto que, por ejemplo, Guillermo Carnero (2009, p. 74) -estudioso atento de la trayectoria de Manuel Reina- califica sin rubor de "pésimo poema», discute la calidad y hasta el hecho de que tenga otra significación, no simplemente la de su carácter encomiástico, laudatorio. Sin embargo, si observamos la datación del texto, vemos que aparece fechado en octubre de 1884 y este dato nos permite pensar en una posibilidad que Carnero obvia. Concurren varias circunstancias que hacen dudar de una aseveración tan categórica y apuntan hacia una mayor consideración. La larga extensión del poema (177 versos) es tan solo equiparable a dos poemas de esa etapa, eso sí, muy significativos ambos: «A Francisco Antonio Gavidia» (octubre de 1884, 162 versos) y «A Víctor Hugo» (120 versos). Por otro lado, debemos tener en cuenta el carácter prácticamente fundador ${ }^{8}$ de un tipo de escritos, en los que Rubén Darío radiografía la trayectoria de un poeta, aborda su significación e incluso anima a no caer en el desaliento con respecto a práctica tan necesaria.

Rubén Darío conoce la trayectoria de Manuel Reina. Es obvio que ha leído, al menos, una parte significativa de su obra poética y, si no lo ha hecho directamente en los volúmenes publicados hasta entonces -Andantes y alegros

8. Así consideraba Octavio Paz al autor de Azul..., como si se tratara del guía de un carmelo poético (Paz, 1991, p. 138). 
y Cromos y acuarelas-, puede haber accedido a ella a través de La Ilustración Española y Americana o de La Diana, la propia revista dirigida por el cordobés. Por otro lado, existen varios detalles determinantes para darnos cuenta de cómo Rubén está al tanto de la figura admirada. Mencionamos más arriba que al principio del poema «Manuel Reina», Rubén sitúa al objeto de su encomio entre los «poetas inspirados» de España. Es curioso que se incluye a Echegaray, al lado de Zorrilla, Campoamor, Manuel del Palacio o Núñez de Arce. De manera explícita, lo que se resalta del que obtendría el Premio Nobel de Literatura en 1904, es que triunfa en las tablas; Rubén le tilda de «emperador del teatro». El joven poeta parece que conoce la buena relación personal entre don José y Manuel Reina. Es seguro que ha leído las colaboraciones del también ingeniero y matemático en la sección científica de la revista del cordobés. Pero lo más sorprendente es que nos remite, incluso, a la orientación que está surgiendo en aquellos años en nuestro autor y que le mueve hacia la creación dramática. Es la época en la que Reina presenta El dedal de plata, su única obra de teatro que llegó a imprimirse y a ponerse en escena. Inspirada en un artículo de François Coppée, se estrenó el 25 de mayo de 1883 en el Teatro Español de Madrid. Coppée era un reconocido poeta, dramaturgo y novelista perteneciente a la escuela parnasiana por la que ambos, Reina y Darío, tuvieron gran estima. Darío llegaría calificar a Reina de $«$ raro $»^{9}$ en nuestro poema de octubre de 1884 y fue precisamente el componente parnasiano el que ha venido utilizándose en mayor medida para definir la obra del cordobés y, como es sabido, del que el nicaragüense reclutó algunos nombres destacados para conformar parte de la veintena de semblanzas incluidas, tras el ensayo «El arte en silencio», en su volumen titulado Los raros (1896).

Por otro lado, Rubén Darío puede estar influido, al escribir este significativo poema, por razones que no son solo de carácter literario, sino también de índole humana. Los propios versos del poema nos lo sugieren, sobre todo hacia el final, en los que el jovencísimo nicaragüense anima desde la otra orilla del Atlántico al vate de Puente Genil. Manuel Reina lleva, desde principios de ese año 1884, asistiendo a un período delicado de su vida. En enero ha tenido que cerrar la revista La Diana y, para terminar de acumular desgracias, su esposa Frasquita cae gravemente enferma y acaba falleciendo con veintisiete años de edad el día 26 del mes de marzo. Dejaba tres hijos: Manuel, con cuatro años; Francisco, con 3 años; y Luis Fernando, con apenas tres meses. La responsabilidad que recae en nuestro autor es inmensa. A ello se suman las

9. Rubén hace uso del término hasta en dos ocasiones. Dice que «el poeta inspirado» produce «raras sinfonías» (v. 84) y que «es lindo y raro» su «arrebatador procedimiento» (v. 102). 
aprehensiones numerosas provocadas por su hipersensibilidad y por una incipiente diabetes. Por consiguiente, parece como si Rubén Darío -conociendo someramente dichos reveses- intentara consolar con ese merecido reconocimiento y ese espaldarazo para que su «estro» poético no se diluya, no llegue a perderse. Recordemos los versos citados más arriba:

$$
\begin{aligned}
& \text { ¡Sí; que escriba un poema revestido } \\
& \text { con esas joyas que sólo él fabrica } \\
& \text { y con esas ideas altas, sumas, } \\
& \text { que hay entre la cabeza de los seres } \\
& \text { favorecidos por la augusta y santa } \\
& \text { disposición del Cielo! [...] (vv. 135-140). }
\end{aligned}
$$

Asimismo, es necesario dar un repaso a lo que son los propios poemas del mismo período creativo de su autor y, concretamente, al que, casi siempre, se publica de manera contigua al que estudiamos aquí, me refiero al dedicado a Francisco Antonio Gavidia, el gran intelectual salvadoreño ideólogo del unionismo centroamericano, que posiblemente, cuando Rubén Darío escribe nuestro poema en 1884, tal vez, estaría en El Salvador y podría ser aquel quien le recomendara la lectura del poeta cordobés que habría ya dado a luz dos de sus poemarios, de curioso título para todo lo que hemos dicho anteriormente referido a lo musical y a lo cromático. Enrique Anderson Imbert recordaba que: «Mientras vivió en Centroamérica, Rubén Darío estuvo en medio de una rosa de los vientos, oyéndolo todo, imitándolo todo, sin orientarse decididamente. Es natural. Tomar conciencia de sí mismo y de la realidad en que se vive y se sueña es un proceso lento y difícil» (Darío, 1993, p. VII). El poema «A Francisco Antonio Gavidia» será el poema que sigue al titulado «Manuel Reina» en la edición de las Poesías completas, al cuidado de Méndez Plancarte (1961). Los dos textos están fechados en octubre de 1884. Rubén Darío reconoció que, desde 1882, Gavidia lo acercó a Victor Hugo y a los modelos parnasianos. Añade Anderson Imbert que dicha época es la de «su estudio de invenciones poéticas francesas. Leyó las colecciones de 1880 a 1884 de la Revue des Deux Mondes y la crónica parisiense de La Ilustración Española y Americana de Madrid» (Darío, 1993, p. X). Además, es el momento en el que se mostrará deslumbrado por Théophile Gautier, François Coppée y Catulle Mendès.

El primer libro de Reina se titula Andantes y alegros (1877) y el segundo Cromos y acuarelas (1878). Solo ya los títulos son verdaderamente significativos. Anoto esa posibilidad porque Gavidia, que está atento a la novedad y también a lo que producen los cenáculos intelectuales peninsulares, seguro que conoce La Diana y es en la revista La Diana donde creo que está la clave y 
el acercamiento personal a lo que le ha ocurrido a Manuel Reina. En La Diana, Manuel Reina ha promovido un proyecto cultural verdaderamente extraordinario, bastante efímero, que ha durado desde 1882 hasta justo enero del año 1884. El último número de La Diana fue el no 24 , tomo II, correspondiente al 22.01.1884. Recuerdo que el poema de Rubén estaba fechado en octubre de ese año. En esa revista, Manuel Reina, además de muchos otros contenidos, lo que había hecho era traducir a algunos de los escritores, que, como es sabido, van a dejar verdaderamente desnortados a los primeros modernistas hispanos. Me estoy refiriendo, claro está, a Gautier, me estoy refiriendo a Baudelaire, me estoy refiriendo a Verlaine, me estoy refiriendo al norteamericano Poe. El aprecio de Rubén Darío por Manuel Reina puede venir precisamente de ese tipo de conocimiento, de ese cordobés que se muestra interesado en recuperar determinadas cuestiones incluso del Romanticismo, que aún pueden ser atractivas, cuestiones del Parnaso, cuestiones del decadentismo y cuestiones que tienen que ver con presentar al público en castellano a esos grandes escritores que van a ser verdaderos dioses para los primeros modernistas.

Santiago Reina López (2005, pp. 63-71), bisnieto del poeta de Puente Genil, ha realizado la catalogación de su obra y, al repasar algunos artículos de La Diana (especialmente el poema encomiástico dedicado a «Sara Bernhardt», poema CXVIII, 1882), repara en una nota que aparece inserta en la revista y que puede resultar crucial para saber si Manuel Reina era conocido a esas alturas en Hispanoamérica. Reina López subraya la importancia del dato porque lo considera fundamental de cara a la fijación de los orígenes del Modernismo ${ }^{10}$. Dicho de otro modo, esa pista nos permitiría el poder asegurar que La Diana, y por tanto la obra de los premodernistas españoles (Reina, Rueda, Blasco y Fernández Shaw) eran leídas en aquellas latitudes ya en 1882. Constatado tal extremo, ayudaría a aclarar bastante el problema. La nota en cuestión la conforma un texto en el que la redacción de la revista se extiende acerca de un pleito fronterizo entre Colombia y Venezuela, de cuyo arbitraje ha sido encargado el rey de España, y promete ocuparse del problema en números sucesivos, «dado los muchos lectores que tiene en Hispanoamérica». Según el bisnieto del director de la revista, esta aclaración «explica el poema "A Manuel Reina” [sic] que, con sólo 17 años, (octubre de 1884), Rubén Darío

10. La polémica sobre la génesis del Modernismo ha dado lugar a una rica bibliografía que es imposible resumir aquí y que, por otra parte, es conocida por el especialista. En todo caso, destaco algunas referencias que guardan relación más directa con el objeto de nuestro estudio: Cernuda (1957), Pérez Poiré (1966), Criado Costa (1979), Cardwell (1983), Gallego Morell (1987 y 2000), Niemeyer (1992), Auladell Pérez (1993), Carnero (2009). 
dedicó al poeta cordobés». A continuación, Reina López reproduce el poema en su integridad y desgrana algunos comentarios:

Habría que destacar cómo, con solo veintiocho años y dos libros publicados, Reina es considerado por el joven Rubén Darío uno de los grandes poetas españoles de su tiempo, a la altura de Núñez de Arce, Zorrilla, Campoamor, Echegaray y Manuel del Palacio («entre ellos / tiene alto puesto Manuel Reina») y de fama internacional («La fama lleva / sus nombres por el mundo»). Afirma, además, la originalidad de su estilo formal y acepta, al menos eso se desprende de sus palabras, haber intentado imitarlo («Muestra Reina un estilo sui generis / difícil de imitar»). También le parecen modernas sus ideas ( «es un poeta / del siglo diecinueve a todas luces»). La temática de «sus cánticos extraños» puede saltar, según él, desde los ambientes urbanos («rostros descompuestos en medio de la orgía», champaña...), a la levedad y dulzura de la naturaleza («aéreas ninfas», «querubes blondos», notas dulces, «onda mansa / y serena del lago rumoroso...»), desde la Edad Media [... al al mundo mitológico [...]; sus versos son [...]; sus estrofas son [...]; pero, a veces, produce «raras sinfonías / en loca exaltación».

Y, más adelante, se plantea algún interrogante acerca de la influencia de Reina en Darío:

¿Acaso no está describiendo Rubén Darío características de su propio estilo posterior? ¿No se trasluce de sus versos la sensación de haber descubierto en la lectura de la poesía de Reina algo nuevo y diferente? [...]

Es indudable, por otra parte, el perfecto conocimiento que Darío tiene de Manuel Reina, no es solo que escriba este poema en una de las estrofas [sic] preferidas de nuestro poeta: el endecasílabo blanco; sino que, además, sabe que este lleva muchos años sin publicar un volumen, por ello, lo anima a hacerlo.

Por último, Reina López insiste en considerar ese tramo temporal como uno de los de mayor intensidad e impacto de la producción de su bisabuelo:

En los años de publicación de La Diana (1882-febrero de 1884) la actividad literaria de Manuel Reina es constante: publica los que serían, prácticamente, sus últimos textos de creación en prosa $[\ldots]$

Para corroborar dicho estado de cosas, es curioso que otro de los primeros, de los que se llaman muchas veces precursores del modernismo, el cubano Julián del Casal, sea uno de los que en esas mismas fechas posee, asimismo, un texto dedicado a Manuel Reina. En diciembre de 1885, unos meses después del poema de Darío sobre el poeta de Puente Genil, Julián del Casal publica un artículo sobre el mismo en La Habana Elegante. Se trata de un texto en prosa en el que el cubano Casal considera a Reina como un «verdadero poeta de tránsito», con «un atinado sentido de modernidad». El 19 de abril de ese año había publicado su «Nocturno», dedicado a la memoria de su padre. 
Esperanza Figueroa (1944, pp. 332-333) dice que: «Durante este paréntesis la "sirena" del sueño poético y las "blancas tumbas" se traspasan a la típica decoración del modernismo, enamorado del lujo» y destaca a ese propósito unas palabras del artículo sobre el cordobés:

Colocado sobre el blanco mármol de la elegante mesa de ébano, bajo un cuadro que representa, a la pálida claridad del astro de la noche, una escena amorosa en el gran canal de Venecia, entre dorado pebetero oriental y luciente jarrón de porcelana de Sèvres, lleno siempre de purpúreas rosas, moradas violetas y níveas azucenas [...]

El texto es sintomático de una sensibilidad que hizo que Julián del Casal también contara con el calificativo de raro:

El 26 de noviembre de 1885 publica Francisco Chacón en El Fígaro unos apuntes que titula «Casal (notas de mi cartera)». Para ese entonces el total de colaboraciones de Casal aparecidas en la prensa se reducía a los poemas: "iUna lágrima!», «El poeta y la sirena», «Huérfano», «Amor en el claustro», «Nocturno», «Desde lejos» y el texto en prosa «Manuel Reina». Seis poemas y un texto en prosa; para una vida literaria que había comenzado en 1881 con la publicación de "¡Una lágrima!" en la revista El Ensayo, no es demasiado. Sin embargo, para Chacón era bastante ya como para hacerlo escribir esas notas en las que el sentimiento central es la extrañeza. Casal es un raro (Víctor Fowler, 2002, p. 42).

La obra de Julián del Casal se sitúa en un período de transición que supone una radical innovación tanto en el género prosístico como en el poético, adelantando las claves fundamentales que van a alimentar el emergente modernismo hispanoamericano junto a figuras de perfil tan destacado como otro cubano, José Martí; el mexicano Manuel Gutiérrez Nájera; o el colombiano José Asunción Silva. El hecho de que en España surjan unos cuantos nombres, como Manuel Reina, Salvador Rueda, Ricardo Gil u otros, que de forma pareja acometen una andadura de revisión y superación de los esquemas románticos, sugiere el análisis comparativo de todas estas figuras de ambas orillas del Atlántico. Por otra parte, el interés de Casal por Europa y su estancia frustrante en España, en donde solo halló eco en Salvador Rueda, nos lleva a poner en contacto al joven poeta cubano con la escritura peninsular del momento desde una doble vertiente: el interés por Europa que movía a Casal como a otros modernistas y la recepción en España de los primeros modernistas hispanoamericanos, dejando aparte a Rubén Darío. Se trata, pues, de abordar la figura de Julián del Casal, por una parte, como iniciador de una poética que alberga numerosas notas de modernidad y, por otra, poner ello en relación con el proceso evolutivo de la poética española durante los últimos años de la Restauración. La relación intelectual y personal que Casal mantuvo en la 
Península muestra el paradigma de la conexión-desconexión que comenzó a aflorar desde entonces. El poeta Agustín Acosta (1945, p. 5) pronunció el 21 de octubre de 1943 unas palabras junto a la tumba de Casal, al conmemorarse el 50 aniversario de su muerte. Merece la pena reproducirlas:

Decíamos que Martí oficiaba en Cuba, sacerdote de los más blancos altares; Díaz Mirón y Gutiérrez Nájera en México; González Prada en el Perú; Ricardo Gil y Manuel Reina en España. Ah, señores, pero en España oficiaba también Salvador Rueda, que fue amigo de Casal. Si en algunos poemas de Casal hiciéramos abstracción de aquella modalidad amarga y pesimista de su espíritu, encontraríamos la sonoridad plástica y recia, el ornamento y la música con que en aquellos años pontificaba sin ser comprendida, la musa soberbia y fecunda de Salvador Rueda.

Y si a algunos de los versos de Casal añadiéramos lo que hay de alegre despreocupación en algunos poemas de Gutiérrez Nájera, en aquellos encontraríamos la garra dulce y suave del Duque Job acariciando el alma de nuestro poeta atormentado.

¿Pero es que Julián del Casal no influyó también sobre Rueda, sobre Reina, sobre Nájera? Contemporáneos como eran, no sería aventurado afirmar influencias recíprocas entre los mismos, ya que todos volaban en un cielo igualmente luminoso, y todos ellos conocían por igual su doloroso oficio.

Una vez más contamos con un testimonio que trasciende lo circunstancial. Supone algo esencial. ¿Qué podemos pensar de ese único texto en prosa del primerizo Julián del Casal? Al igual que con el caso de Rubén Darío, asistimos a una especial querencia hacia lo que representaba la novedad de la poesía de Manuel Reina.

Frente a la calificación de poco importante, casi nada significativo o completamente irrelevante, sorprende su gran extensión. Solo equiparable a su gran poema coetáneo sobre la historia del libro. Parece que escribir una tirada de casi doscientos endecasílabos permite inferir algo de interés por la personalidad que trata de elogiar. Por consiguiente y, al menos, a efectos de lo que es la obra primeriza del gran poeta nicaragüense, insistimos en calificarlo de texto esencial. Texto esencial de un momento de vagidos que auguraba unos tiempos posteriores, en los que el nomadismo de Rubén le conduciría a seguir cultivando el género del poema metapoético y culturalista, que habla de poesía y de poetas. Muchos de esos textos, tanto en prosa como en verso, son generales («Yo persigo una forma...», «Los poetas»...), pero otros son nominales. Son piezas, «gemas» -por emplear su propio término alusivo a los de Reina en El Jardín de los poetas-, en las que Rubén llega, en ocasiones, a la excelsitud. Nadie duda hoy que algunos de los más excelentes textos que forman parte del canon dariano son esos famosos poemas dedicados a Verlaine, Valle-Inclán, Antonio Machado o Juan Ramón Jiménez. 
De tal manera, que podemos concluir, sin pecar de exagerados, que el poema titulado «Manuel Reina» es un texto esencial de la primera etapa poética de Rubén Darío porque en él apreciamos la proyección que el pontanés ejercía en el nicaragüense, la posibilidad de entendimiento como temprano homenaje y el adelanto del fino instinto para destacar los nombres que más tarde o más temprano conformarían las líneas de evolución literaria de la época modernista, que viene aceptando con mayor o menor consenso la crítica académica. Como sucede con las obras artísticas y hasta con la vida en general, contamos, en ocasiones, con acontecimientos, conductas, creaciones, etc., que influyen en nosotros, trascienden su tiempo, y lo hacen por un determinado valor constituyente que no tiene por qué ir aparejado a la calidad o a la perfección. La atención del joven Darío por Manuel Reina y la escritura de su poema así titulado, nos proporciona, más que un texto esencial por sus altas cualidades poéticas, un testimonio de cuál era el objeto de interés, las expectativas estéticas y el modelo que seguir. En esto radicaría la esencialidad del poema que comentamos, más allá de las posibles descalificaciones provenientes de la naturaleza de la composición o de la constatación de cierta impericia en su autor, por razón de la corta edad. Lo que más sobresale del caso, es el deslumbramiento ${ }^{11}$ que advertimos en aquel joven por la figura del poeta español. Juan Ramón Jiménez (1961, p. 156) nos contó en la elegía que dedicó a su muerte: «Ha sido indudablemente el poeta lírico de su generación». Y añadió: «El rey era, entonces, don Manuel Reina. Parnasiano impecable, con la exaltación exterior de aquel Leopardi que tuvo una estrella en su joroba, fue nuestro Leconte de L'Isle, corazón de mármol y rosas - menos frondoso que el corazón del poeta francés- alma vacía a fuerza de suntuosidad». Por esos años, Rubén ha quedado prendado por el modo versificador de Reina y aún no es el tiempo de su dedicación a otros primeros modernistas peninsulares como, por ejemplo, Salvador Rueda, al que ofrecería tanto apoyo hasta el momento de la enemistad y la rivalidad explicitada en una cruda controversia. Katharina Niemeyer (1992, p. 326) recuerda cómo Salvador Rueda evolucionó hacia «un estricto y beligerante anti-modernismo», incluso tras la

11. Antonio Gallego Morell (2000, p. 592-593) defendía que el entusiasmo era lo que unía a los dos poetas. Es probable que tal percepción la recuperara al leer a Octavio Paz que, en «El caracol y la sirena» nos recordaba cómo el entusiasmo era «el origen de la poesía para Novalis» (Paz, 1991, p. 140). Tras comparar el poema «La legión sagrada», fechado en 1891 y publicado posteriormente en La vida inquieta de Manuel Reina, con la «Marcha triunfal» de Rubén Darío, Gallego Morell afirma que: «Existe una asombrosa semejanza en la musicalidad de ambos poemas, en la puesta en escena del episodio épico, en la comunión en un mismo clima de entusiasmo. Yo creo que acertaríamos en proclamar: en sus poemas Darío y Reina coinciden en el "entusiasmo"». 
reconciliación en lo personal con el nicaragüense. La propia Niemeyer (1992, p. 327) subraya, frente a la posición de Rueda y otros premodernistas, la inquietud por lo nuevo del cordobés y el apoyo a los jóvenes valores líricos en la órbita del Modernismo. Manuel Reina valoró muy positivamente, por ejemplo, La copa del rey de Thule (1900), de Francisco Villaespesa, «la piedra de toque del Modernismo castellano». Nuestro poeta de Puente Genil opinó que este poemario fuera, «a pesar de sus irreverencias retóricas, la gloriosa exaltación de la juventud más original y potente de nuestras letras». En definitiva, en el caso de Manuel Reina, adivinamos otro tipo de relación, la del referente para cultivarnos en el oficio, la del vate respetado por encima de todo, la del maestro o, al menos, la de uno de los maestros. Por eso, reivindicamos que este poema de Darío es uno de sus textos esenciales.

Los años 2016 y 2017 se presentan como años darianos, como 2005 y 2006 fueron años conmemorativos para Manuel Reina. Con uno y con otro, se nos ofrece la posibilidad de una doble celebración de manera inmediatamente sucesiva. Este año hace un siglo que falleció Rubén Darío. El año próximo es el del 150 aniversario de su nacimiento. Los dos poetas dejaron este mundo el año en el que alcanzaban los 49 de edad. No sobrepasaron el medio siglo de vida. Seguramente, a causa de algún conjuro numerológico de su admirado Pitágoras ${ }^{12}$, el hecho de que las fechas del nacimiento y de la muerte de Rubén Darío resulten con dígitos finales contiguos, 1867 y 1916, propiciarán siempre que a la hora del recuerdo de las efemérides, empecemos conmemorando su desaparición y terminemos por celebrar su alumbramiento. Algo similar ocurre con Manuel Reina, que nace en 1856 y muere en 1905. Llegados aquí, solo queda exorcizar el misterio.

\section{Bibliografía}

ACosTA, Agustín, «Una extraña evocación o Julián del Casal», Revista cubana, vol. XIX (enero-junio 1945), pp. 5-15.

Aguilar Piñal, Francisco, La obra poética de Manuel Reina, Madrid, Editora Nacional, 1968.

12. Lo numerológico nos conduce a lo rítmico. Ricardo Gullón nos aproximó al predicamento que tuvo Pitágoras entre los modernistas. Lo sustancial de la doctrina pitagórica «consistía en una concepción rítmica del universo y de la vida que los modernistas no sólo aceptaron sino convirtieron en idea central determinante de la creación poética. [...] El pitagorismo fue visto como un sistema concebido para poner orden en el caos; los números son cifras mágicas que revelan -si acaso no ocultan- la significación secreta de las cosas» (R. Gullón, 1999, p. 110). 
ALARCÓN Sierra, Rafael, "Valores simbolistas en la literatura española del primer tercio del siglo XX», en Anales de Literatura Española, n 15 (2002), pp. 71- 92.

Auladell PÉREZ, Miguel Ángel, «Zorrilla y los primeros modernistas españoles», en J. Blasco, R. de la Fuente y A. Mateos (eds.), José Zorrilla. Una nueva lectura, Valladolid, Fundación Jorge Guillén, 1995, pp. 221-230.

CARDWEll, Richard A., «Rubén Darío y Salvador Rueda: dos versiones del Modernismo», Revista de Literatura, 45 (1983), pp. 55-72.

CARnero, Guillermo, «Manuel Reina ante el reto modernista», Cuadernos Hispanoamericanos, $n^{\circ}$ 709-710 (julio-agosto 2009), pp. 71-97.

CASAl, Julián del, Poesía completa y prosa selecta, ed. Álvaro Salvador, Madrid, Verbum, 2002, 410 pp.

CERnUdA, Luis, Estudios sobre poesía española contemporánea, Madrid, Guadarrama 1957.

Concha, Jaime [1975], Rubén Darío, Madrid, Júcar (col. Los Poetas), 1984, $2^{a}$ ed. [Recoge obra del Rubén joven, anterior a Abrojos en un epígrafe titulado "De sus Primeros poemas", pp. 125-128: "A ti", "Cámara oscura", "Sotto voce"].

Criado Costa, Joaquín, «Un andaluz en la génesis del Modernismo poético: Manuel Reina», Boletín de la Real Academia de Córdoba de Ciencias, Bellas Letras y Nobles Artes, vol. I, no 100 (1979), pp. 99-121.

DARío, Rubén [1990], Antología de poesía y prosa, ed. Miguel Ángel Auladell Pérez, Alicante, Aguaclara, 1992, $1^{a}$ reimpr. [El poema «Manuel Reina», en pp. 24-29].

- [1901], «Los poetas», en España contemporánea, prólogo de Antonio Vilanova, Barcelona, Lumen, 1987, p. 202.

- [1896], Los raros, ilustraciones de Enrique Ochoa, Madrid, Mundo Latino, vol. VI de las obras completas (editadas por su hijo Rubén), 1918.

-, Obras completas I. Poesía, ed. Julio Ortega con la colaboración de Nicanor Vélez, Prólogo de José Emilio Pacheco, Barcelona, Galaxia Gutenberg/Círculo de Lectores, 2007. [El poema «Manuel Reina», en pp. 867-872].

- Obra poética, ed. José Carlos Rovira con la colaboración de Sergio Galindo, Madrid, Biblioteca Castro, 2011.

- Obras poéticas completas (edición revisada), introd. y ensayo bibliográfico de Federico Carlos Sainz de Robles, Madrid, Aguilar, 1945.

—, Poesía [1977], introd. y selección de Jorge Campos, Madrid, Alianza, 1982, $4^{\text {a }}$ ed.

--- [1952], Poesía. Libros poéticos completos y antología de la obra dispersa, Estudio preliminar de Enrique Anderson Imbert, ed. Ernesto Mejía Sánchez, Madrid, FCE, 1993 ( $2^{\text {a }}$ reimpr.)

-, Poesías completas [1952], ed., introd. y notas de Alfonso Méndez Plancarte, Madrid, Aguilar, 1961, 9a ed. [El poema «Manuel Reina» en las pp. 198-203; fechado en octubre de 1884]. 
-, Poesías completas, ed. Alfonso Méndez Plancarte, aumentada con nuevas poesías y otras adiciones por Antonio Oliver Belmás, Madrid, Aguilar, 1968, 11ª ed.

—, Rubén Darío Esencial, ed. Arturo Ramoneda, Madrid, Taurus (Esenciales Taurus), 1991.

DeLGADO,Jaime, «Rubén Darío, poeta transatlántico», Cuadernos Hispanoamericanos, $n^{\circ}$ 212-213 (agosto-septiembre 1967), pp. 289-331.

DíAZ-PLAJA, Guillermo, La dimensión culturalista en la poesía castellana del siglo XX, Discurso de recepción del académico de número..., Madrid, Real Academia Española, 1967, pp. 42-53.

Esteban-P. Del CAmpo, Ángel, «Hispanismo y becquerianismo en José Martí», Anales de Literatura Hispanoamericana, nº 20 (1991), pp. 145-153.

FERnÁndEZ, Teodosio, Rubén Darío, Madrid, Historia 16/Quórum/Quinto Centenario, 1987.

FigUEROA, Esperanza, «Apuntes sobre Julián del Casal», Revista Iberoamericana, vol. VII, $n^{\circ} 14$ (febr. 1944), pp. 329-335.

-, «Julián del Casal y el modernismo», Revista Iberoamericana, vol. XXXI, nº 59 , (enero-junio 1965), pp. 47-69.

—, «Bibliografía cronológica de la obra de Julián del Casal», vol. Xxxv, nº 68 , (mayo-agosto 1969), pp. 385-399.

FOWLER, Víctor, «Casal disputado y una nota al pie», La Habana Elegante, Segunda época, $\mathrm{n}^{\circ} 18$ (verano 2002), p. 42.

GALLEGo Morell, Antonio, «Manuel Reina en la espiral del Modernismo», en G. Carnero (ed.), Actas del Congreso Internacional sobre el Modernismo español e hispanoamericano y sus raíces andaluzas y cordobesas, Córdoba, Diputación Provincial, 1987, pp. 373-380.

—, «La poesía modernista de Manuel Reina», en G. Carnero (ed.), Actas..., pp. 381-389. También en: Homenaje a José María Martínez Cachero: investigación y crítica, Oviedo, Universidad de Oviedo, 2000, vol. 2, pp. 591-603.

GARCÍA MARTín, José Luis, «La poesía culturalista», en La segunda generación poética de posguerra, Badajoz, Excma. Diputación Provincial (Col. "Rodríguez Moñino", no 5), 1986, pp. 205-210.

Gullón, Ricardo [1964], Direcciones del Modernismo, Madrid, Alianza, 1990.

JiMÉNEZ, Juan Ramón, «Elejía accidental por don Manuel Reina», en La corriente infinita, Madrid, Aguilar, 1961, pp. 156-168.

LóPez Estrada, Francisco, Rubén Dario y la Edad Media: una perspectiva poco conocida sobre la vida y la obra del escritor, Barcelona, Planeta, 1971.

Marasso, Arturo, Rubén Dario y su creación poética, La Plata, Facultad de Humanidades y Ciencias de la Educación (Biblioteca Humanidades, t. XIII) 1934.

Anales, 28 (2016), pp. 15-38 
MARTÍNEZ-TOlENTINO, Jaime, Literatura hispánica e hispanoamericana. Tres autores revalorados: Ricardo Palma, Julián del Casal y Jacinto Benavente, Kassel, Reichenberger, 1992.

Niemeyer, Katharina, La poesía del Premodernismo español, Madrid, CSIC, 1992.

Onís, Federico de [1934], Antología de la poesía española e hispanoamericana, ed. y estudio introductorio de Alfonso García Morales, Sevilla, Renacimiento, 2012.

ORY, Eduardo de [1916], Manuel Reina. Estudio biográfico, seguido de numerosas poesías de este autor no coleccionadas en sus libros, Cádiz, Editorial España y América, s.a.

PAZ, Octavio, «El caracol y la sirena: Rubén Darío», en Fundación y disidencia. Dominio hispánico, Obras completas, ed. del autor, Barcelona, Círculo de Lectores, 1991, vol. 3, pp. 137-171.

PÉREZ POIRÉ, Margarita, «Manuel Reina y Montilla, primera voz modernista», Boletín de la Biblioteca Nacional, tomo XVII, segunda época, $\mathrm{n}^{\circ}$ 3-4 (juliodiciembre 1966), pp. 73-88.

Reina sanuel, Andantes y alegros. Versos de..., Madrid, Impr. A. Flórez y Cía., 1877.

- Cromos y acuarelas (Cantos de nuestra época), Madrid, Impr. de Fortanet, 1878.

—, La Diana. Revista de política, literatura, ciencias y arte, Madrid, 1882-1884.

—, El Jardín de los Poetas, Madrid, Imp. Hijos de M. G. Hernández, 1899.

ReIna López, Santiago, Manuel Reina: Catalogación completa de su obra. Análisis de su poesía en el tránsito al Modernismo, Córdoba, Diputación de Córdoba, 2005.

SALinas, Pedro [1948], La poesía de Rubén Darío. Ensayo sobre el tema y los temas del poeta, Barcelona, Península, 2005.

TORRES, Edelberto, La dramática vida de Rubén Darío, Barcelona, Grijalbo, 1966.

TORRES RioseCO, Arturo [Calpe, 1925], Precursores del Modernismo, New York, Las Américas Publishing, 1963. 